\title{
Biosorption of heavy metal arsenic from Industrial Sewage of Davangere District, Karnataka, India, using indigenous fungal isolates
}

\author{
D. Abhijna Tanvi ${ }^{2}$ K. M. Pratam ${ }^{2}$ R. T. Lohit ${ }^{2}$ B. K. Vijayalakshmi ${ }^{2}$ T. N. Devaraja ${ }^{3}$ M. Vasudha ${ }^{1} \cdot$ A. Ramesh ${ }^{1}$. \\ Prashantkumar S. Chakra ${ }^{1} \cdot$ Devaraja Gayathri ${ }^{1}$ (])
}

Received: 13 May 2020 / Accepted: 3 October 2020 / Published online: 22 October 2020

(c) Springer Nature Switzerland AG 2020

\begin{abstract}
Contamination of soil and water bodies with heavy metals like arsenic (As) is of major concern, since arsenic is non-biodegradable, toxic and causes ill effects to gastrointestinal system, skin, liver, kidney or neurological functions. In addition, animals affected by arsenic pollution through fodder intern enter to food chain. Hence, there is an urgent need to address heavy metal arsenic pollution especially through bioremediation. In this context, biosorption with indigenous microbiota has gained more interest in recent years as it is cost-effective, eco-friendly approach and with no adverse effects. In the present study, arsenic (As III)-resistant strains of fungi were isolated from soil samples collected from various locations of industrial sewage disposal sites of Davangere District, India, and screened. Among five fungal isolates, Aspergillus spp APR-1 and APR-2 showed greater resistance to arsenic in the laboratory conditions. In order to increase the surface area for biosorption, APR-1 and APR-2 isolates were immobilized on Luffa aegyptiaca (sponge gourd) (an agro-waste as biosorbent). With $250 \mathrm{mM}$ arsenic solution, Aspergillus spp APR-1 and APR-2 showed biosorption of 53.94 and 52.54\%, respectively, on inductively coupled plasma-optical emission spectrometry analysis and the adsorption of the fungal isolates on sponge gourd was confirmed using scanning electron microscopy. APR-1 isolate was further characterized by $18 \mathrm{~s}$ rDNA typing and identified as Aspergillus niger. Industrial scale application perhaps is taken up using selected fungal strains and mitigates the arsenic pollution in urban sewage.
\end{abstract}

Keywords Biosorption · Luffa aegyptiaca $\cdot$ Aspergillus niger $\cdot$ Arsenic

\section{Introduction}

A major deal of concern has been articulated over problems of soil and water contamination with heavy metals, due to overexploitation of natural resources: rapid industrialization and urbanization [1]. These heavy metals may originate from different sources in urbanized areas, such as vehicle emissions, textile, leather, tannery, mining, electroplating, galvanizing, pigment and dyes, metallurgical and paint industrial discharges, heavy metal-containing fertilizers, and pesticides in agricultural fields, sewage sludge and urban soil sludge. These are typical contaminants as well as useful indicators of environment pollutions.

Arsenic (As) is a frequent and naturally occurring element that is found in the earth's crust, organic world,

Electronic supplementary material The online version of this article (https://doi.org/10.1007/s42452-020-03622-0) contains supplementary material, which is available to authorized users.

Devaraja Gayathri, gayathridevaraja@gmail.com | ${ }^{1}$ Department of Studies in Microbiology, Davangere University, Shivagangothri, Davangere 577007, India. ${ }^{2}$ Rashtrotthan Vidya Kendra, Nittuvalli, Davangere 577004, India. ${ }^{3}$ ICAR-Taralabalu Krishi Vigyan Kendra, Kadalivana, Davangere 577004, India. 
marine water and groundwater. It contaminates drinking water, through various means like the natural process involves weathering reactions, volcanic emissions, biological activity along with various human activities like combustion of fossil fuels in power plants, mining activities, nonferrous smelting, petroleum refining and with the use of arsenical pesticides and herbicides. Severe implications occur to human health due to the chronic exposure to arsenic-polluted drinking water [2-4]. The tolerable limit as per World Health Organization guidelines for contamination in drinking water is $10 \mu \mathrm{g} / \mathrm{L}$ [5]. The long-time exposure with arsenic concentrations more than $100 \mathrm{ppb}$ can lead to skin lesions, skin cancer, increased infant mortality, reduced birth weight, neurological impairments in children and adults, impaired motor function, neuropathy, bronchiectasis, lung, bladder, liver and kidney cancer, hypertension, impaired glucose tolerance in pregnant women, inflammation, disorders in memory and intellectual function, steatosis, ischemic heart diseases, disturbed hormonal system, diabetes mellitus, DNA damage, etc. [6, 7].

There are different technologies at industrial level to remediate the immense intimidation to the environment as well as ill-health effects on human beings by heavy metal pollution. These may include electrochemical separation, chemical precipitation, membrane separation, coagulation, reverse osmosis, ion exchange, adsorption resins and others. However, these approaches have limitations as they involve large capital investment, labor or intensive operational cost and they are not effective in removing metal ions in ppm levels. Some of the methods generate harmful sludge which requires further sludge treatment and there is a disturbance of indigenous soil microflora and irreversible changes in soil physicochemical properties [8, 9]. Hence, there is a vital need for costeffective eco-friendly approaches. In this context, bioaccumulation and biosorption have an influential effect on the removal of heavy metal contamination, although bioaccumulation has lower kinetics and lesser efficiency due to the uptake obstruct caused by toxic heavy metal ions as compared to biosorption [10].

Therefore, biosorption is a powerful technology with immense potential for heavy metal removal and recovery even from ppm to ppb levels in aqueous suspension which has led to an alternative approach for the treatment of industrial wastewater [11]. Biosorption is a physicochemical and metabolically independent process based on a variety of mechanisms using biological material such live or dead microorganisms, plant or agricultural wastes. The removal of arsenic is not metabolically controlled; it is passively bound to the biomass and entrapped in the cell wall of a dead or live organism. The foremost benefit of using this technology is its cost-effectiveness, in situ remediation at the contaminated site, and there is no production of any harmful byproducts [12,13]. Effective biosorbents play an important role in biosorption, and generally used biosorbents are microorganisms like bacteria, fungi, yeasts, algae, weeds and agricultural waste products. There are many proposed ways by which the removal of heavy metals have been done, for instance, many interactions occur with extracellular polymeric substances such as complexation, adsorption, ion-exchange, precipitation, and entrapment in inner spaces of the cell membrane [14, 15] which are expensive, cumbersome and not sustainable. Arsenic occurs in four oxidation states $(+5,+3,0$ and -3 ) among which As III is more toxic. Bioremediation is innocuous alternative to conventional physical or chemical methods. Microbial-mediated bioremediation of arsenic involves reduction, oxidation, intracellular accumulation and methylation.

In the present study, indigenous fungi from industrial sewage were isolated and Luffa aegyptiaca (sponge gourd) was used as a biosorbent agent. The study was focused on efficient immobilized fungal biomass on Luffa sponge for arsenic adsorption and provided an unconventional, safe cost-effective and eco-friendly way of arsenic removal from a contaminated water source. Agricultural lignocellulosic material Luffa sponge which has fibrous network matrix along with carboxyl and phenolic groups with good porosity can be used for immobilizing fungal hyphae and both together form a good cost-effective, eco-friendly biosorbent [16-18]. Fungal biomass has a large surface area and shows a high affinity toward metal ion, and both biologically active and inactive fungal biomass has the competence to adsorb metal ions. Further, there is an urgent need of remediation for local pollution problem by indigenous organisms, perhaps this biotechnological tool would help in cleaning up the environment efficiently.

\section{Materials and methods}

\subsection{Sample collection}

Heavy metals contaminated soil samples were collected (industrial sewage) from different regions of Davangere, Davangere District, India $\left(14.4666^{\circ} \mathrm{N} 75.9242^{\circ} \mathrm{E}\right)$. The samples were transferred to clean sterile polythene bags, and the samples were processed within $24 \mathrm{~h}$ after collection.

\subsection{Isolation and screening of heavy metal-resistant fungi}

For isolation and screening autoclaved potato dextrose agar (PDA) media supplemented with $250 \mathrm{mM}$ arsenic heavy metal (As III) was used. The samples were serially 
diluted up to $10^{-7}$ using $0.85 \%$ physiological saline. The sample was subjected to pour plate technique and after solidification of the agar plates, incubated at $28 \pm 2{ }^{\circ} \mathrm{C}$ for 3-4 days. Later, the fungal colonies were enumerated, and colony morphology and microscopic studies were carried out. For identification of fungal isolates, $72 \mathrm{~h}$ mycelial samples were briefly stained with Lacto phenol cotton blue and observed under the microscope (40X) (Olympus) [29].

\subsection{Extraction of genomic DNA}

The potential fungi were grown on $50 \mathrm{ml}$ of PDB media at $28 \pm 2^{\circ} \mathrm{C}$ for $5-6$ days, and the mycelial mat was harvested, washed thrice using distilled water and ground with liquid nitrogen. Using cetyl trimethyl ammonium bromide (CTAB) method, genomic DNA was extracted and the purity of the DNA was checked spectrophotometrically $[19,20]$.

\subsection{PCR of ITS region}

Further, fragments of the ITS1and ITS4 were amplified by using ITS1 and ITS4 primers. The final volume of each reaction mixture was $30 \mu \mathrm{L}$ containing $1 \mathrm{X}$ PCR buffer, $200 \mu \mathrm{M}$ each dNTPS, $1.4 \mathrm{mM} \mathrm{MgCl}_{2}, 1 \mu \mathrm{L}$ of each primer (100 nmol), $1.0 \cup$ Taq DNA polymerase and $20 \mathrm{ng}$ of genomic DNA. Later, it was programmed to conduct 30 cycles after an initial denaturation of $4 \mathrm{~min} / 94^{\circ} \mathrm{C}$. Each amplification cycle consisted of three steps: denaturation $\left(94^{\circ} \mathrm{C} / 45 \mathrm{~s}\right)$, annealing $\left(56^{\circ} \mathrm{C} / 45 \mathrm{~s}\right)$ and elongation $\left(72^{\circ} \mathrm{C} / 1 \mathrm{~min}\right)$. Final elongation at $72^{\circ} \mathrm{C}$ for $5 \mathrm{~min}$ was carried out. The amplified fragments were analyzed by gel electrophoresis in 1 ×TEB buffer as per Sambrook and Russel [21]. Later, 1\% agarose gels were treated with ethidium bromide and the bands visualized under UV light.

\subsection{ITS region sequencing}

The PCR products were purified according to the manufacturer's instructions using GenElute ${ }^{\mathrm{TM}}$ PCR clean-up kit and sequencing was carried out using $\mathrm{ABI}$ automated DNA sequencer. The sequencing PCR was set up using ABI-BigDye ${ }^{\circledast}$ Terminatorv3.1 Cycle sequencing Kit [22].

\subsection{Analysis of sequence}

For the identification of the isolates, BLAST analysis was carried out in the NCBI database, highest homology and total score were noted, and sequences were retrieved. Multiple sequence alignments of the obtained sequence and reference sequences retrieved from GenBank were used to generate a phylogenetic tree using the software MEGA-X.

\subsection{Biomass preparation}

The selected fungal isolates were mass cultured to prepare biomass using potato dextrose broth (PDB) $\left(28 \pm 2{ }^{\circ} \mathrm{C}\right.$ for 3-4 days). Later, fungal mat was harvested by filtration using a muslin cloth and thoroughly washed with double distilled water and dried at $40^{\circ} \mathrm{C}$ for $24 \mathrm{~h}$. Harvested biomass contained both metabolically active and less active biomass which was used for further studies.

\subsection{Immobilization of fungi on Luffa sponge}

Agriculture fields around Davangere, India, have abundant source of Luffa aegyptiaca, sponge gourd fruits, and they were sliced into pieces of $6 \mathrm{~cm}$ in diameter, soaked with hot water then washed thrice with tap water, and later the sponge was oven-dried at $60-70^{\circ} \mathrm{C}$ for $24 \mathrm{~h}$ and autoclaved for $20 \mathrm{~min}$ at $121^{\circ} \mathrm{C}$. For immobilization of fungal cultures on to the Luffa sponge, the spores of isolated fungi were inoculated in the potato dextrose broth and incubated in a shaker incubator at $28^{\circ} \mathrm{C}$ for $5-6$ days and it was harvested from the culture media and dried at $40^{\circ} \mathrm{C}$ for $48-72 \mathrm{~h}$.

\section{Evaluation of sequestration and biosorption capacity of fungi using analytical methods}

\subsection{Biosorption of arsenic}

Biosorption capacity of the immobilized fungal biomass on Luffa sponge was assessed by adding $250 \mathrm{mM}$ arsenic (As III) in growth medium and the immobilized sponge in a flask and which was incubated at $28^{\circ} \mathrm{C}$ for 3-4 days in a rotary shaker. Then, the biomass and solution were subjected to qualitative and quantitative analysis.

\subsection{Determination of heavy metals in samples}

To study the surface morphology and biosorption capacity of immobilized fungi, scanning electron microscope-energy-dispersive X-ray spectroscopy (SEM-EDX) was used. The morphological changes in the fungal cultures before and after As (III) adsorption were analyzed. $0.1 \mathrm{~g}$ of the immobilized fungal sponge was placed on a tape and placed on stage of SEM-EDX (X MAS $20 \mathrm{~mm}^{2}$, UK), designed by coating the sample with a thin layer of gold and observed under 100X of magnification for Arsenic III treated/untreated samples. 


\subsection{ICP-OES}

Samples were analyzed in inductively coupled plasmaoptical emission spectrometry (ICP-OES) using standard methods established by APHA for metals determination was carried out and percentage of biosorption was calculated by the formula:

Percentage of biosorption $=\frac{\text { Control-Sample reading }}{\text { Control }} \times 100$

\section{Results and discussion}

\subsection{Isolation and screening of As III-resistant fungal isolates}

Four soil samples were collected from industrial sewage and soil samples, from which a total of 17 different fungal colonies were isolated and they were screened for arsenic biosorption capacity by spreading them on PDA agar supplemented with $250 \mathrm{mM}$ arsenic (As III) in it. Out of 17 isolates, only five isolates showed good growth which was used for further analysis and named them as APR $1-5$ and the fungal genera were identified by microscopic observation using lactophenol blue staining technique.

For further analysis, APR-1 and APR-2 were selected as they showed the highest growth on PDA supplemented with arsenic, and the results are tabulated in Table 1. Cardenas-Gonzalez and their research group [23] have reported that Aspergillus sp., Paecilomyces sp., Cladosporium sp. and Mucor sp. could remove $1 \mathrm{mg} / \mathrm{L}$ of arsenic (V) metal solution, whereas Srivastava lead study group [24] reported that species Aspergillus, Trichoderma, Penicillium, Rhizopus, Sordaria and Neocosmospora were very efficient in removing and tolerant to the arsenic of concentration about $5000 \mathrm{mg} \mathrm{I}^{-1}$. In the present study, potential fungal isolate APR-1 showing high biosorption was identified as Aspergillus niger with accession number MT875332 (Fig. 1).

Table 1 Fungal isolates (APR-1 to APR-5) exhibiting resistance to arsenic (As III) heavy metal

\begin{tabular}{lll}
\hline Strain code & Fungal isolate & $\begin{array}{l}\text { Growth in } \\
\text { diameter } \\
(\mathrm{mm})\end{array}$ \\
\hline APR-1 & Aspergillus niger & $12.33 \pm 0.57$ \\
APR-2 & Aspergillus.spp & $9.33 \pm 0.57$ \\
APR-3 & Rizopus.spp & $2.66 \pm 0.28$ \\
APR-4 & Fusarium.spp & $4.33 \pm 0.057$ \\
APR-5 & Penicillium.spp & $3.16 \pm 0.28$ \\
\hline
\end{tabular}
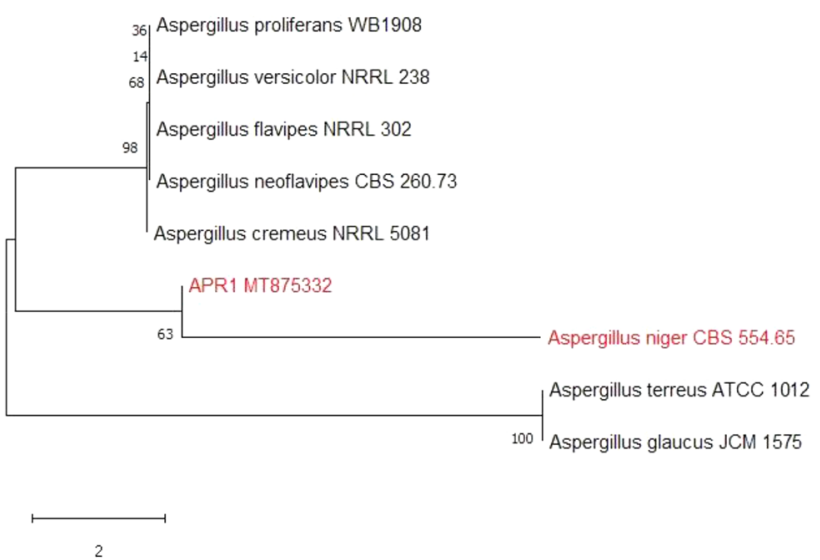

Fig. 1 Phylogenetic tree construction for the fungal isolate APR-1

\subsection{Immobilization of APR-1 and APR-2 on luffa sponge}

Luffa aegyptiaca is a common and inexpensive plant material with extensive matrix network made up of hollow lignocellulosic microfibers of diameter 15-20 $\mu \mathrm{m}$, makes it a good fibrous network biosorbent material which provides good contact between adsorbed substances and its surface. It has been reported that L. aegyptiaca-reinforced epoxy composites have been developed by the hand layup method with Luffa fiber untreated (with the presence of hydroxyl group from cellulose and lignin fiber) and treated conditions. Treated Luffa fiber composite showed better properties through addition of modified Luffa fiber as reinforcement and also tensile and flexural properties [27]. In an another report, Luffa cylindrical was used as adsorbent for the removal of methylene blue dye from aqueous solutions at different temperatures and dye concentrations. Thermodynamics and kinetics of adsorption revealed that methylene blue (MB) adsorption was exothermic and spontaneous [28]. Therefore, locally available luffa sponge was selected for the present study and used for fungal adsorbant material (Fig. 2).

\subsection{Evaluation of biosorption capacity of the designed bioabsorbent}

The adsorption capacity of designed biosorbent was evaluated by using $250 \mathrm{mM}$ concentration of the arsenic solution with designed biosorbent of APR-1 and APR-2, and control was prepared with an arsenic solution with plain luffa sponge without fungal biomass and after incubation period biomass was separated and the residual filtrate was analyzed for residual arsenic which was further confirmed by ICP-OES. The samples APR- 1 and APR-2 showed 53.92 and $52.54 \%$ of biosorption, respectively,

SN Applied Sciences 

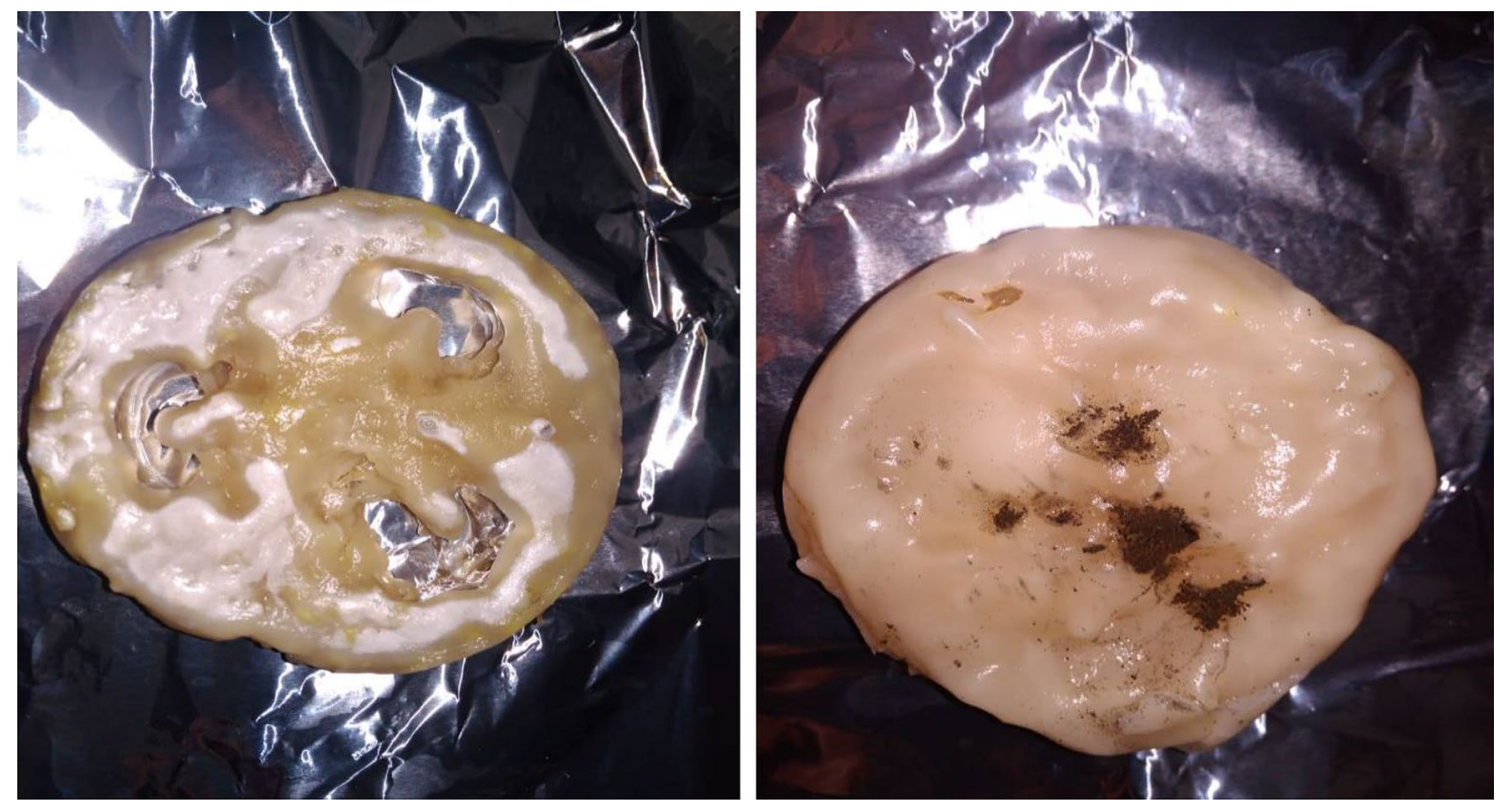

Fig. 2 Immobilized fungal isolates APR-1 and APR-2 on luffa sponge

and the results are tabulated in Table 2. The scientific data available with respect to arsenic biosorption using luffa sponge are limited; however, reports on other heavy metal biosorption using luffa sponge are available. For example, $13 \%$ from $3 \mathrm{mM}$ lead solution was bioabsorbed by immobilized Phanerochaete chrysosporium on luffa sponge [25]. Phanerochaete chrysosporium, when immobilized on L.cylindrica, was able to remove hexavalent chromium $\mathrm{Cr}$ (VI) and it showed maximum biosorption at $\mathrm{pH} 2$ and temperature $40^{\circ} \mathrm{C}$ with $67-92 \%$ of biosorption [26]. In addition, Aspergillus niger and Aspergillus terreus immobilized on luffa sponge where alkali-treated showed biosorption 51 and 46\%, respectively [18]. However, in the present study, up to the level of $53.92 \%$ biosorption of As (III) was observed.

\subsection{Adsorption of arsenic on immobilized fungal biomass; scanning electron microscopy studies}

Scanning electron microscopy (SEM) observation evidenced uniform adherence of fungal biomass immobilized on luffa sponge (Fig. 3a). Further, uniform growth of fungal biomass on luffa sponge before adsorption is illustrated in Fig. 3b, whereas arsenic-treated fungal immobilized sample showed the adsorption of arsenic on fungal biomass with a change in morphology and clumsy deposits on the fungal mycelia proving the efficacy of arsenic adsorption on presently designed fungal immobilized luffa sponge illustrated in Fig. 3c, d. Similar distinct change in the morphology with muddy deposits of lead on fungal mycelia indicates the efficacy of adsorption of $A$. terreus [18].

\subsection{ICP-OES quantitative analysis of data}

Quantitative data were the one according to IS 3025 (Part 2): 2004 RA-2014, where the control had an arsenic concentration of $17,995.87 \mathrm{mg} / \mathrm{L}$, whereas the fungal isolates immobilized on luffa sponge showed the decreased concentration APR-01 and showed $8292.14 \mathrm{mg} / \mathrm{L}$, and APR-02 showed $8539.89 \mathrm{mg} / \mathrm{L}$, when calculated by the formula method. The percentage of biosorption was 53.92 and $52.94 \%$, respectively, and the results are tabulated in Table 2. Similar study using Aspergillus spp adsorbed $20-23 \%$ of lead as confirmed by ICP-OES
Table 2 ICP-OES data; percentage of biosorption by two potential fungal isolates

\begin{tabular}{lllcl}
\hline Lab code & Parameters & Protocol & $\begin{array}{l}\text { Arsenic concen- } \\
\text { tration (mg/L) }\end{array}$ & $\begin{array}{l}\text { Percentage } \\
\text { of biosorp- } \\
\text { tion }\end{array}$ \\
\hline 8316 ( APR-01) & Arsenic & IS 3025 (Part 2): 2004 RA-2014 & 8292.14 & $53.92 \%$ \\
8317 (APR- 02) & (As III) & & 8539.89 & $52.54 \%$ \\
8318 (Control) & & & $17,995.87$ & 0 \\
\hline
\end{tabular}



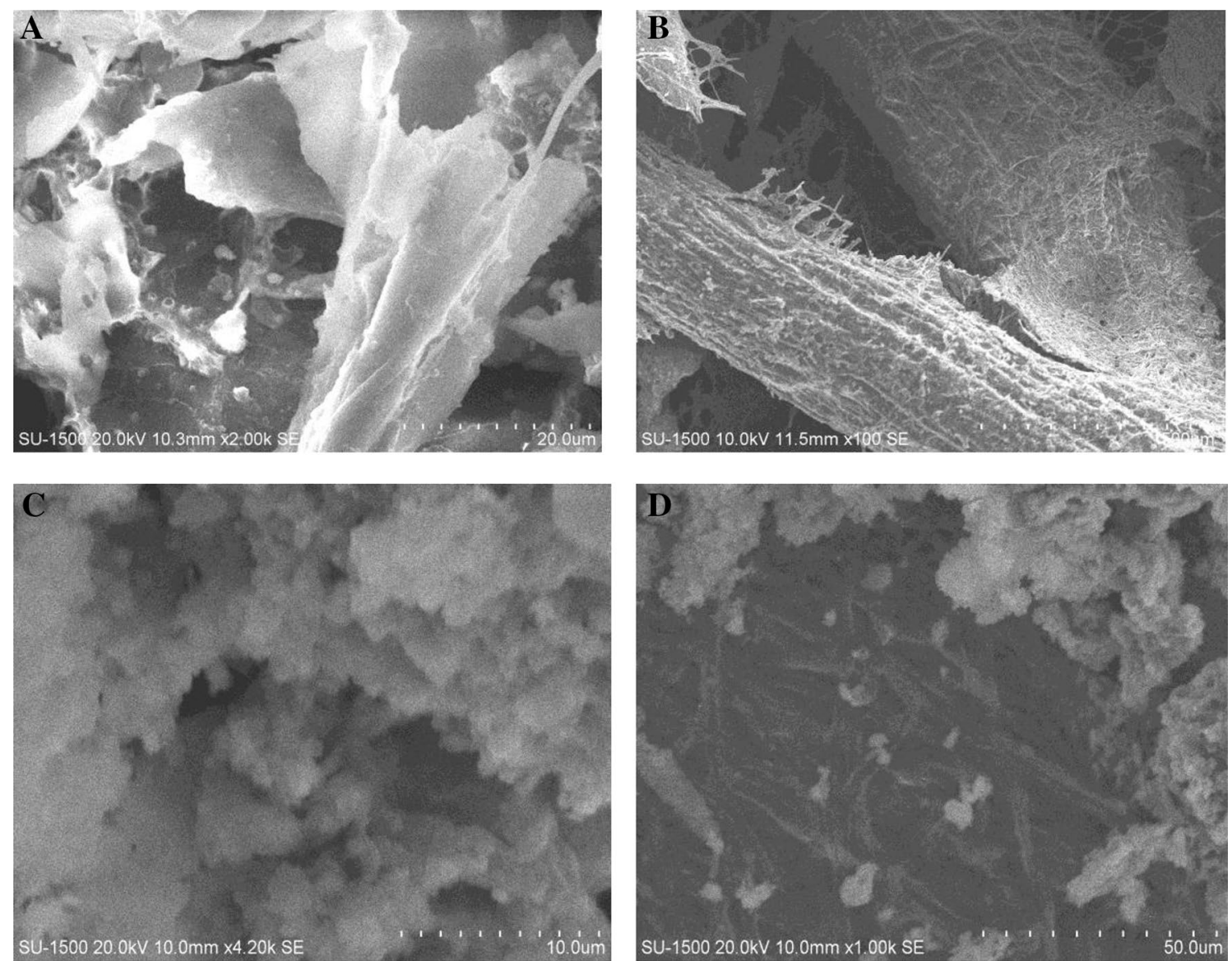

Fig. 3 SEM micrographs showing surface morphology a structure of L. aegyptiaca, $b$ fungal immobilization on luffa sponge, $\mathbf{c}$ and $\mathbf{d}$ showing adsorption of arsenic on fungal mycelia immobilized on luffa sponge

[18]. Several reports have been documented about lead biosorption process $[18,25]$, while arsenic biosorption in the present study is first of its kind.

\section{Conclusion}

The present study contributes significantly on biosorption of highly toxic, environmental pollutant heavy metal arsenic by using specially designed bioadsorbent using an agro-waste material Luffa aegyptiaca which was found easily in the study area. Adsorption of fungal biomass to the sponge gourd increased the efficiency of biosorption using two fungal strains of Aspergillus spp APR-1 and APR-2 and showed 53.92 and $52.54 \%$ of biosorption, respectively. Arsenic biosorption using immobilized agro-waste material has been first of its kind and the promising result was obtained for industrial level in situ biosorption using reusable biosorbant Luffa aegyptiaca sponge on immobilization of Aspergillus niger APR-01 and APR-02.

\section{SN Applied Sciences}

Acknowledgements The authors sincerely acknowledge support rendered by Davangere University, Davangere, India and The Management of RVK, Davangere, India.

\section{Compliance with ethical standards}

Conflict of interest The authors declare that there is no conflict of interest among authors or institution or material.

\section{References}

1. WangY BLO (2014) Heavy metal pollution in Guangdong Province, China, and the strategies to manage the situation. Front Environ Sci. https://doi.org/10.3389/fenvs.2014.00009

2. Wei BG, Yang LS (2010) A review of heavy metal contaminations in urban soils, urban road dusts and agricultural soils from China. Microchem J 94:99-107

3. Guo JX, Lin Hu, Yand PZ, Tanabe K, Miyatalre M, Chen Y (2007) Chronic arsenic poisoning in drinking water in inner mongolia and its associated health effects. J Environ Sci Health A 42(12):1853-1858. https://doi.org/10.1080/109345207015669 18 
4. Smedley PL, Kinniburgh DG (2002) A review of the source, behaviour and distribution of arsenic in natural waters. Appl Geochem 17:517-568

5. DeSesso J, Jacobson C, Scialli A, Farr C, Holson J (1998) An assessment of the developmental toxicity of inorganic arsenic. Reproduct Toxicol 12:385-433

6. Kapaj S, Peterson H, Liber K, Bhattacharya P (2006) Human health effects from chronic arsenic poisoning-a review. J Environ Sci Heal A 41:2399-2428

7. Naujokas MF, Anderson B, Ahsan H, Aposhian HV, Graziano JH, Thompson C, Suk WA (2013) The broad scope of health effects from chronic arsenic exposure: update on a worldwide public health problem. Environ Health Perspect 121:295-302

8. Wang LK, Fahey EM, Wu ZC (2004) Dissolved air flotation. In: Wang LK, Hung YT, Shammas NK (eds) Physicochemical treatment processes. Humana Press, New Jersey, pp 431-500

9. Wingenfelder U, Hansen C, Furrer G, Schulin R (2005) Removal of heavy metals from mine waters by natural zeolites. Environ Sci Technol 39:4606-4613

10. Gupta VK, Nayak A, Agarwal S (2015) Bioadsorbents for remediation of heavy metals: current status and their future prospects. Environ Eng Res 20:1-18

11. Volesky B (1994) Advances in biosorption of metals: selection of biomass types. FEMS Microbiol Rev 14:291-302

12. Davis TA, Volesky B, Mucci A (2003) A eview of the biochemistry of heavy metal biosorption by brown algae. Water Res 37:4311-4330

13. Vijayaraghavan K, Yun YS (2008) Bacterial biosorbents and biosorption. Biotechnol Adv 26:266-291

14. Ghadah M, Al-Fawzan A-S (2018) Adsorption study of heavy metal ions from aqueous solution by nanoparticle of wild herbs. Egypt J Aquat Res 44:187-194. https://doi.org/10.1016/j. ejar.2018.07.006

15. Park D, Yun YS, Park JM (2010) The past, present, and future trends of biosorption. Biotechnol Bioprocess Eng 15:86-102

16. Hu MZC, Reeves M (1997) Biosorption of uranium by Pseudomonas aeruginosa strain CSU immobilized in a novel matrix. Biotechnol Prog 13:60-70

17. Li X-M, Liao D-X, Xue-qin Xu, Yang Qi, Zeng G-M, Zheng W, Guo $L$ (2008) Kinetic studies for the biosorption of lead and copper ions by Penicillium simplicissimum immobilized within loofa sponge. J Hazard Mat 159:610-615. https://doi.org/10.1016/j. jhazmat.2008.02.068

18. Sriharsha DV, Kumar L, Savitha J (2017) Immobilized fungi on luffa cylindrica: an effective biosorbent for the removal of lead. J Taiwan Inst Chem Eng 80:589-595

19. Swamy CT, Gayathri D, Devaraja TN, Bandekar M, Stecy Dsouza E, Meena MT, Ramaiah N (2016) Plant growth promoting potential and phylogenetic characteristics of a lichenized nitrogen fixing bacterium. Enterobacter cloacae. J Basic Microbiol. https://doi. org/10.1002/jobm.201600197

20. Donnell K, Cigelnik E, Weber NS, Trappe JM (1997) Phylogenetic relationships among Ascomycetous truffles and the true and false morels inferred from $18 \mathrm{~S}$ and $28 \mathrm{~S}$ Ribosomal DNA sequence analysis. Mycologia 89:48-65

21. Sambrook J, Russell D (2001) Molecular cloning: a laboratory manual, 3rd edn. Cold Spring Harbour Laboratory Press, NY

22. Alurappa R, Bojegowda MRM, Kumar V, Mallesh NK, Chowdappa S (2014) Characterisation and bioactivity of oosporein produced by endophytic fungus Cochliobolus kusanoi isolated from Nerium oleander L. Nat Prod Res 28:2217-2220

23. Cardenas-Gonzalez JF, Acosta-Rodriguez I, Teran-Figueroa $Y$, Rodriguez-Perez AS (2017) Bioremoval of arsenic (V) from aqueous solutions by chemically modified fungal biomass. 3 Biotech $7(3): 226$

24. Srivastava PK, Vaish A, Dwivedi S, Chakrabarty D, Singh N, Tripathi RD (2011) Biological removal of arsenic pollution by soil fungi. Sci Total Environ 409:2430-2442

25. Iqbal M, Saeed A (2007) Biosorption of reactive dye by loofa sponge-immobilized fungal biomass of Phanerochaete chrysosporium. Process Biochem 42:1160-1164

26. Verma DK, Hasan SH, Ranjan D, Banik RM (2014) Modified biomass of Phanerochaete chrysosporium immobilized on luffa sponge for biosorption of hexavalent chromium. Int J Environ Sci Technol 11:1927-1938

27. Ichetaonye SI, Madufor IC, Yibowei ME, Ichetaonye DN (2015) Physico-mechanical properties of luffa aegyptiaca fiber reinforced polymer matrix composite. Open J Comp Mater 05:1 10 117. https://doi.org/10.4236/ojcm.2015.54014

28. Demir H, Top A, Balköse D, Ülkü S (2008) Dye adsorption behavior of Luffa cylindrical fibers. J Hazard Mater 153(1-2):389-394. https://doi.org/10.1016/j.jhazmat.2007.08.070

29. Shamly V, Kali A, Srirangaraj S, Umadevi S (2014) Comparison of microscopic morphology of fungi using Lactophenol Cotton Blue (LPCB), iodine glycerol and congo red formaldehyde staining. J Clini Diagn Res 8(7):DL01-DL02. https://doi.org/10.7860/ JCDR/2014/8521.4535

Publisher's Note Springer Nature remains neutral with regard to jurisdictional claims in published maps and institutional affiliations. 